\title{
Prevalence and socio-demographic correlates of psychological health problems in Chinese adolescents during the outbreak of COVID-19
}

\author{
Shuang-Jiang Zhou ${ }^{1} \cdot$ Li-Gang Zhang $^{1} \cdot$ Lei-Lei Wang $^{1} \cdot$ Zhao-Chang Guo $^{2} \cdot$ Jing-Qi Wang ${ }^{3} \cdot$ Jin-Cheng Chen ${ }^{4}$. \\ Mei Liu ${ }^{5} \cdot X_{i}$ Chen $^{6} \cdot$ Jing-Xu Chen ${ }^{1}$ (I)
}

Received: 31 March 2020 / Accepted: 23 April 2020 / Published online: 3 May 2020

(c) Springer-Verlag GmbH Germany, part of Springer Nature 2020

\begin{abstract}
Psychological health problems, especially emotional disorders, are common among adolescents. The epidemiology of emotional disorders is greatly influenced by stressful events. This study sought to assess the prevalence rate and socio-demographic correlates of depressive and anxiety symptoms among Chinese adolescents affected by the outbreak of COVID- 19 . We conducted a cross-sectional study among Chinese students aged 12-18 years during the COVID-19 epidemic period. An online survey was used to conduct rapid assessment. A total of 8079 participants were involved in the study. An online survey was used to collect demographic data, assess students' awareness of COVID-19, and assess depressive and anxiety symptoms with the Patient Health Questionnaire (PHQ-9) and the Generalized Anxiety Disorder (GAD-7) questionnaire, respectively. The prevalence of depressive symptoms, anxiety symptoms, and a combination of depressive and anxiety symptoms was $43.7 \%, 37.4 \%$, and $31.3 \%$, respectively, among Chinese high school students during the COVID-19 outbreak. Multivariable logistic regression analysis revealed that female gender was the higher risk factor for depressive and anxiety symptoms. In terms of grades, senior high school was a risk factor for depressive and anxiety symptoms; the higher the grade, the greater the prevalence of depressive and anxiety symptoms. Our findings show there is a high prevalence of psychological health problems among adolescents, which are negatively associated with the level of awareness of COVID-19. These findings suggest that the government needs to pay more attention to psychological health among adolescents while combating COVID- 19 .
\end{abstract}

Keywords Depression $\cdot$ Anxiety $\cdot$ COVID-19 $\cdot$ Prevalence $\cdot$ Adolescents

Shuang-Jiang Zhou and Li-Gang Zhang contributed equally to this work. They should be regarded as joint first authors.

Electronic supplementary material The online version of this article (https://doi.org/10.1007/s00787-020-01541-4) contains supplementary material, which is available to authorized users.

Jing-Xu Chen

chenjx1110@163.com

1 Beijing HuiLongGuan Hospital, Peking University HuiLongGuan Clinical Medical School, Beijing 10096, China

2 The First High School of Juxian, Rizhao, Shandong, China

3 Binhai Eco-City School-Tianjin Nankai High School, Tianjin, China

4 The Experimental Middle School of Chengde, Chengde, Hebei, China

5 The Hospital of Nankai University, Tianjin, China

6 Hebei Tangshan Foreign Language School, Tangshan, Hebei, China

\section{Introduction}

The 2019 novel coronavirus disease (COVID-19) first broke out in Wuhan, Hubei Province, China, on 31 December 2019, and it was later declared an international public health emergency by the World Health Organization (WHO) [1]. The novel coronavirus disease has spread to 201 countries/ territories outside of China and infected 634,835 patients globally [2] (81,470 in China [3]) as of March 29, 2020. It is worrying that so many people and countries have been affected so quickly. The outbreak of COVID-19 has caused mental health problems among the public and health care workers in China [4, 5]. For instance, it has caused public panic and mental health stress [4]. The increasing number of confirmed cases and the increasing number of outbreakaffected provinces and countries have led to the public's fears that they may be infected. In particular, adolescents are a vulnerable group that is presenting with more and more complex issues [6]. 
Mental health is considered to be the most essential condition for a good quality of life. Adolescents with good mental health can bring their happiness and selfconfidence into adulthood, thus providing the ability to cope with adversity [7]. Mental health disorders account for $16 \%$ of the global burden of disease and injury among people aged 10-19 years [8]. It is estimated that 10-20\% of children and adolescents throughout the world are troubled by mental health problems [9]. Globally, depression is the fourth leading cause of disease and disability among adolescents aged 15-19 years, and the 15th for those aged 10-14 years. Meanwhile, anxiety is the ninth leading cause of disease and disability for adolescents aged 15-19 years and sixth for those aged 10-14 years [10]. Studies have reported high detection rates of mental problems in Chinese children and adolescents, ranging from 10.7 to $27.6 \%$ [11-15]. Various emotional or behavioral problems affect at least 30 million Chinese children and adolescents under 17 years of age [16]. Further studies showed that the incidence of behavioral and emotional problems was $17.6 \%$ among Chinese school children and adolescents aged 6-16 [17]. The mental health problems of adolescents include conduct disorders, emotional disorders, self-harm, eating disorders, and hyperkinetic disorders [10, 17-19]. Additionally, there is more and more evidence that the prevalence of adolescent emotional disorders is increasing [20]. For example, the 12-month prevalence of major depressive episodes in adolescents increased from $8.7 \%$ in 2005 to $11.3 \%$ in 2014 in the United States [21].

Stressful events are potent adverse environmental factors that can predispose individuals to psychiatric disorders, in particular depression [22-24]. In addition, studies have shown that during an epidemic outbreak, the public experiences negative emotional responses, such as anxiety and depression symptoms [25, 26]. Current studies have shown that COVID-19 causes moderate-to-severe symptoms of anxiety and depression in about one-third of adults for Chinese people [27]. The National Health Commission has released guidelines to promote psychological crisis intervention for patients, people under medical observation, medical workers, and civilians during the COVID-19 outbreak [28]. However, it is not clear what is the occurrence and distribution of depressive and anxiety symptoms in adolescents. Therefore, it is necessary to quickly assess depressive and anxiety symptoms related to emergencies for civilians, especially adolescents [29].

The objective of the current study was to assess the prevalence of two specific mental symptoms, anxiety and depression, and their socio-demographic correlates among adolescents in the Chinese population during the COVID-19 outbreak.

\section{Methods}

\section{Design and subjects}

We conducted this cross-sectional study using an online survey to assess mental health problems from March 8 to March 15, 2020. Junior and senior high school students in China aged 12-18 years were invited to participate in the online survey through the Wenjuanxing platform (https:// www.wjx.cn/app/survey.aspx). In total, 8140 participants took part in the survey. After removing the data of participants with incomplete questionnaires, 8079 participants from 21 provinces and autonomous regions were included in the analysis. These regions can represent the overall conditions of China. There is no significant difference in the infection rate of COVID-19 in other regions except Hubei. We divided the participants into from Hubei region and from other regions. The province of Hubei has a population of 59,270,000 and includes the city of Wuhan; Hubei province incurred the highest rate of infections and deaths in China.

Approval for the study was obtained from the Ethics Committee of Beijing HuiLongGuan Hospital. All the participants provided online informed consent to participate in the study.

\section{Assessment tools and procedure}

A data collection sheet was designed to collect basic socio-demographic information and students' awareness of COVID-19 (COVID-19 knowledge, prevention and control measures, projections of COVID-19 trend), and two specific mental symptoms, depressive and anxiety symptoms, were assessed through the online survey. The questions about the awareness of COVID-19 asked participants to select responses from a self-made questionnaire. For the first questions, respondents were asked about their familiarity with information about prevention and control of COVID-19, with responses ranging from 1 ("very unfamiliar") to 10 ("very familiar"). In the second question, respondents were asked if they had taken all the optional prevention and control measures against COVID-19 to avoid infection, and the response range was from 1 ("very consistent") to 10 ("very inconsistent"). In the third question, respondents were asked about their attitudes towards the projections of COVID-19 trend, ranging from 1 ("very pessimistic") to 10 ("very optimistic").

Depressive symptoms were assessed by the Patient Health Questionnaire (PHQ-9) [30-33], which consists of nine items. The PHQ-9 is a simple, highly effective self-assessment tool for depression. Participants are asked 
to report the presence of nine problems, including depression and interest decline, in the last 2 weeks on a 4-point scale ranging from "nearly every day" (3 points) to "not at all" (0 points) [31,33]. The scores for symptom severity were 5-9 for mild, 10-14 for moderate, and 15-19 moderately severe, 20-27 for severe. The PHQ-9 has a good internal consistency, with a Cronbach's alpha coefficient between 0.80 and 0.90 [30-33]. Reliability and validity in the general population, as well as in patients with mental disorders, have been demonstrated [34, 35]. PHQ-9 has been widely used to assess depressive symptoms in adolescents [36, 37].

Anxiety symptoms were assessed by the Chinese version of the Generalized Anxiety Disorder scale (GAD-7) [38, 39], which measures seven symptoms. Participants are asked how often they were bothered by each symptom during the last 2 weeks. The response options are "not at all," "several days," "more than half the days," and "nearly every day," scored as $0,1,2$, and 3 , respectively. The scores for symptom severity were 5-9 for mild, 10-14 for moderate, and 15-21 for severe $[38,39]$. Good retesting reliability and validity for GAD-7 have been confirmed in Chinese people [40]. The Cronbach's alpha is between 0.90 and $0.92[38,41]$. The scale has been used in many studies to assess anxiety symptoms in adolescents $[36,37,42]$.

\section{Statistical analysis}

The dataset was analyzed using SPSS version 24.0 (IBM SPSS, IBM Corp., Armonk, NY, USA). For demographic data, Chi-squared tests were used to analyze categorical variables. The scores for COVID-19 knowledge, prevention and control measures, and projections of the COVID-19 trend fit the normal distribution, so we used an independent-samples $t$ test to compare the difference between the groups with and without depressive symptoms. The same method was used to compare the difference between the groups with and without anxiety symptoms. Logistic regression was used to analyze the predictors of depression and anxiety symptoms. With versus without depressive symptoms and with versus without anxiety symptoms represent dichotomous dependent variables. The level of significance was set at 0.05 (two-sided).

\section{Results}

A total of 8140 junior and senior high school students $(12-18$ years old, median $=16)$ were invited to participate in the online survey; 8079 fulfilled the study inclusion criteria and completed the assessments, giving a response rate of $99.3 \%$. Table 1 shows the socio-demographic characteristics and their associations with depressive and anxiety symptoms. Our results showed differences in depressive and anxiety symptoms among students from different regions. Univariate analysis found that the proportion of depressive symptoms among students in cities was lower than that in rural areas (37.7\% versus $47.5 \%$ ), as was the proportion of anxiety symptoms (32.5\% versus $40.4 \%)$. The proportion of male students with depressive and anxiety symptoms was lower than that of female students (41.7 versus $45.5 \%$; $36.2 \%$ versus $38.4 \%$ ). Depressive and anxiety symptoms differed between grades. With increasing grade (from junior grade one to three and from senior grade one to three), the proportion of students with depressive and anxiety symptoms increased.

Table 2 shows the proportion of students with different levels of depressive and anxiety symptoms. Mild and moderate depressive and anxiety symptoms were most common. The rate of mild depression was $26.4 \%$, while that of moderate depression was $10.1 \%$; meanwhile, the rate of mild
Table 1 Socio-demographic characteristics and association with depressive and anxiety symptoms $(N=8079)$

\begin{tabular}{|c|c|c|c|c|c|c|c|c|}
\hline \multirow[t]{2}{*}{ Variables } & \multirow[t]{2}{*}{$n$} & \multirow[t]{2}{*}{$\%$} & \multicolumn{3}{|c|}{ Depressive symptoms } & \multicolumn{3}{|c|}{ Anxiety symptoms } \\
\hline & & & $n$ & $\%$ & $P$ & $n$ & $\%$ & $P$ \\
\hline Gender & & & & & 0.001 & & & 0.038 \\
\hline Male & 3753 & 46.5 & 1566 & 41.7 & & 1358 & 36.2 & \\
\hline Female & 4326 & 53.5 & 1967 & 45.5 & & 1662 & 38.4 & \\
\hline Region & & & & & $<0.001$ & & & $<0.001$ \\
\hline City & 3103 & 38.4 & 1169 & 37.7 & & 1009 & 32.5 & \\
\hline Rural area & 4976 & 61.6 & 2364 & 47.5 & & 2011 & 40.4 & \\
\hline Grade & & & & & $<0.001$ & & & $<0.001$ \\
\hline Junior grade one & 625 & 7.8 & 200 & 32.0 & & 177 & 28.3 & \\
\hline Junior grade two & 2248 & 27.9 & 820 & 36.5 & & 756 & 33.6 & \\
\hline Junior grade three & 882 & 10.9 & 404 & 45.8 & & 347 & 39.3 & \\
\hline Senior grade one & 2220 & 27.6 & 1,000 & 45.0 & & 801 & 36.1 & \\
\hline Senior grade two & 1486 & 18.4 & 739 & 49.7 & & 610 & 41.0 & \\
\hline Senior grade three & 596 & 7.4 & 357 & 59.9 & & 317 & 53.2 & \\
\hline
\end{tabular}


Table 2 The rate of different severities of depressive and anxiety symptoms $(N=8,079)$

\begin{tabular}{|c|c|c|c|c|c|c|}
\hline \multirow[t]{2}{*}{ Variables } & \multicolumn{2}{|c|}{ Depressive symptoms } & \multicolumn{2}{|c|}{ Anxiety symptoms } & \multicolumn{2}{|c|}{$\begin{array}{l}\text { Comorbid depres- } \\
\text { sion and anxiety } \\
\text { symptoms }\end{array}$} \\
\hline & $n$ & $\%$ & $n$ & $\%$ & $n$ & $\%$ \\
\hline None & 4546 & 56.3 & 5059 & 62.6 & 5552 & 68.7 \\
\hline Mild & 2131 & 26.4 & 2184 & 27.0 & - & - \\
\hline Moderate & 816 & 10.1 & 596 & 7.4 & - & - \\
\hline Moderately severe & 367 & 4.5 & - & - & - & - \\
\hline Severe & 219 & 2.7 & 240 & 3.0 & - & - \\
\hline Mild to severe & 3533 & 43.7 & 3020 & 37.4 & 2527 & 31.3 \\
\hline
\end{tabular}

anxiety was $27.0 \%$, and that of moderate anxiety was $7.4 \%$. The proportion of all of the participating students with mild-to-severe depressive symptoms was $43.7 \%$, and the proportion of all of the students with mild-to-severe anxiety symptoms was $37.4 \%$. The prevalence of comorbid depressive and anxiety symptoms was $31.3 \%$ among all the participants. As shown in Figs. 1a and 2a, the prevalence of depressive symptoms ranged from $39.6 \%$ to $64.0 \%$ from March 8
Fig. 1 The trend of depressive and anxiety symptoms during the survey period

\section{A Depressive symptoms trend using the PHQ-9*}

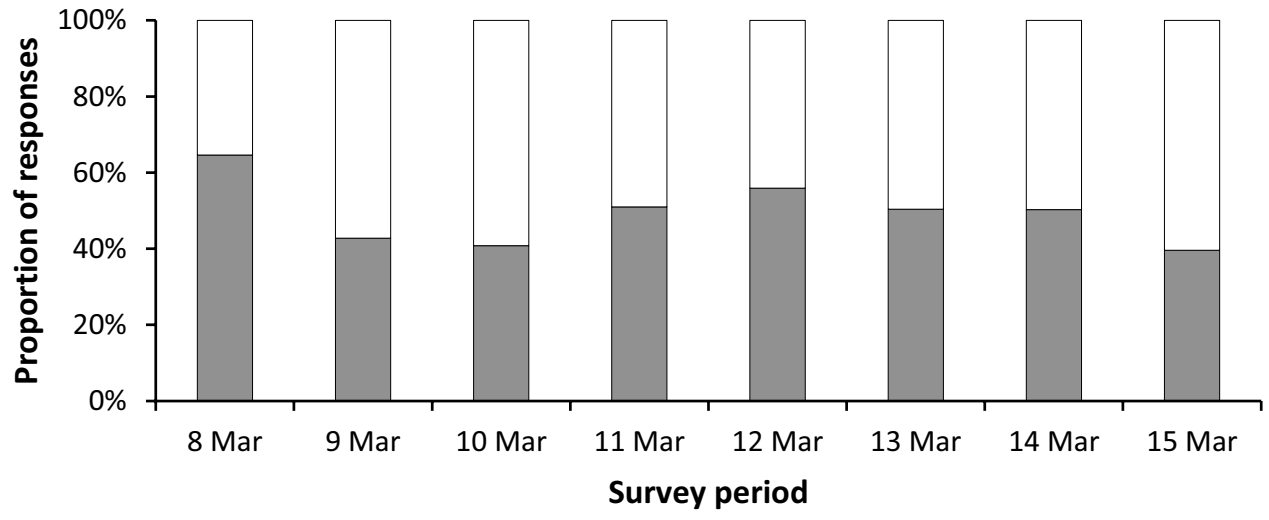

*PHQ-9 score greater than 4 indicates depressive

$\square$ Depressed $\square$ Not depressed

\section{B Anxiety symptoms trend using the GAD-7*}

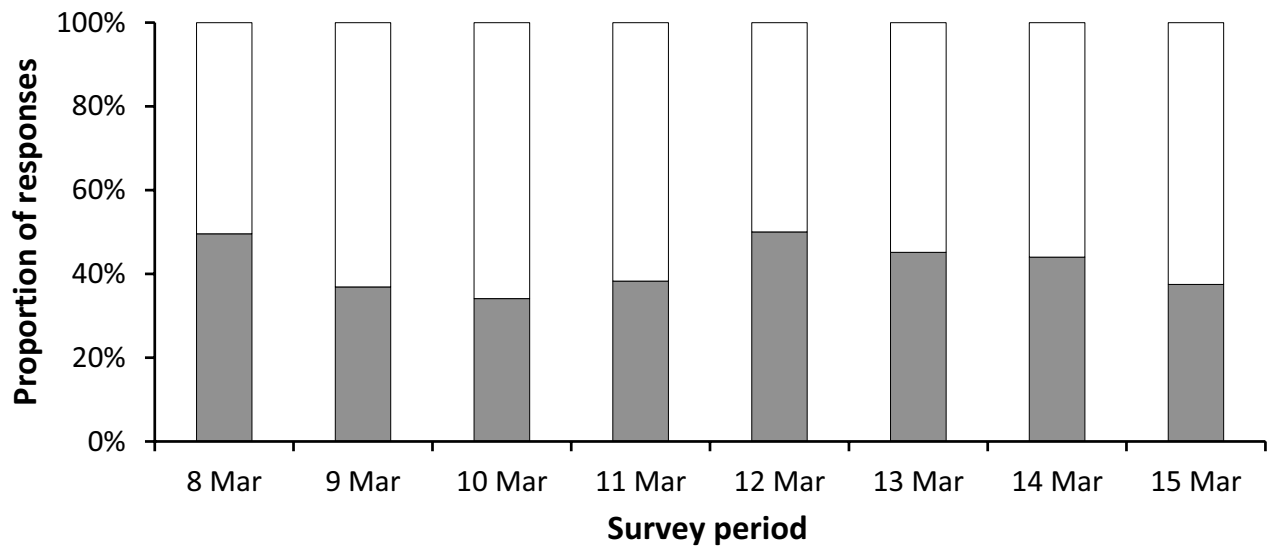

*GAD-7 score greater than 4 indicates anxiety

$\square$ Anxious $\quad \square$ Not anxious 
Fig. 2 The proportion of depressive and anxiety symptom items
A Percentages of adolescents endorsing specific PHQ symptoms

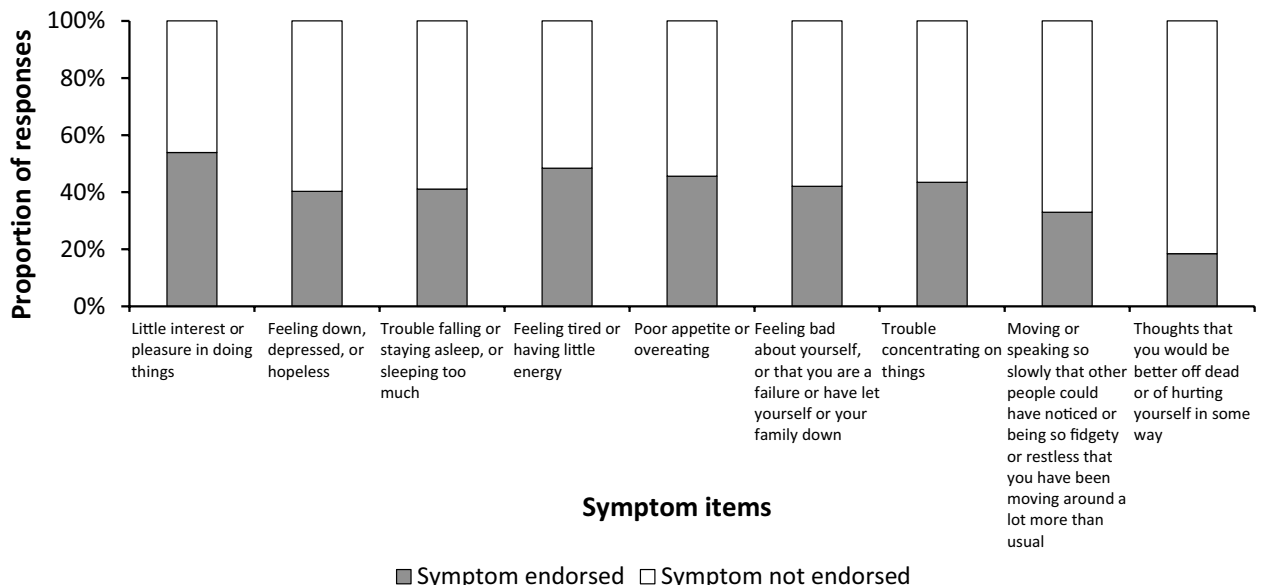

B Percentages of adolescents endorsing specific GAD symptoms

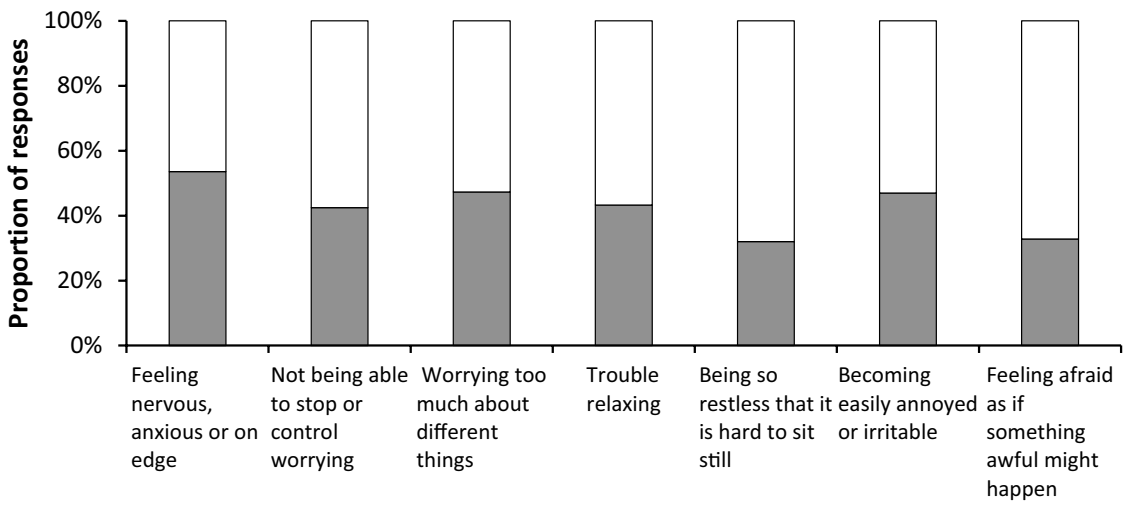

Symptom items

$\square$ Symptom endorsed $\quad \square$ Symptom not endorsed to March 15, 2020. Little interest or pleasure in doing things (53.9\%), feeling tired or having little energy (48.4\%), poor appetite or overeating (45.6\%) are common signs. As shown in Figs. $1 \mathrm{~b}$ and $2 \mathrm{~b}$, anxiety symptoms ranged from 34.1 to $50.0 \%$ from March 8 to March 15, 2020. Feeling nervous, anxious or on edge (53.6\%), worrying too much about different things (47.3\%), becoming easily annoyed or irritable (47.0\%) are the most common symptoms.

Table 3 presents the relationship between COVID-19 cognition and depressive and anxiety symptoms. The scores for
COVID-19 knowledge, prevention and control measures, and projections of the COVID-19 trend were higher among students without depressive and anxiety symptoms than in the students with depressive and anxiety symptoms.

Table 4 presents the results of multivariable logistic regression analysis. In the multivariable model, female gender was the higher risk factor for depressive and anxiety symptoms $\left(\mathrm{OR}_{\mathrm{DE}}=1.15,95 \% \mathrm{CI} 1.05-1.26 ; \mathrm{OR}_{\mathrm{AN}}=1.10\right.$, 95\% CI 1.001-1.21). With regard to provinces, we found that Hubei province was a risk factor for depressive and anxiety

Table 3 The relationship between COVID-19 cognition and depressive and anxiety symptoms $(N=8079)$

\begin{tabular}{lllllll}
\hline Variables & $\begin{array}{l}\text { With depressive } \\
\text { symptoms M (SD) }\end{array}$ & $\begin{array}{l}\text { Without depressive } \\
\text { symptoms M (SD) }\end{array}$ & $P$ & $\begin{array}{l}\text { With anxiety } \\
\text { symptoms M (SD) }\end{array}$ & $\begin{array}{l}\text { Without anxiety } \\
\text { symptoms M (SD) }\end{array}$ & $P$ \\
\hline COVID-19 Knowledge & $6.35(2.21)$ & $7.20(2.24)$ & $<0.001$ & $6.41(2.24)$ & $7.08(2.25)$ & $<0.001$ \\
Prevention and control measures & $7.67(2.30)$ & $8.59(2.02)$ & $<0.001$ & $7.70(2.29)$ & $8.48(2.08)$ & $<0.001$ \\
Projections of COVID-19 trend & $6.98(2.61)$ & $8.08(2.39)$ & $<0.001$ & $6.78(2.67)$ & $8.09(2.34)$ & $<0.001$ \\
\hline
\end{tabular}


Table 4 Socio-demographic and awareness of COVID-19 correlates of depressive and anxiety symptoms $(N=8079)$

\begin{tabular}{|c|c|c|c|c|c|c|}
\hline \multirow[t]{2}{*}{ Variables } & \multicolumn{3}{|c|}{ Depressive symptoms } & \multicolumn{3}{|c|}{ Anxiety symptoms } \\
\hline & OR & $95 \% \mathrm{CI}$ & $P$ & OR & $95 \% \mathrm{CI}$ & $P$ \\
\hline \multicolumn{7}{|l|}{ Gender } \\
\hline Male & 1 & & & 1 & & \\
\hline Female & 1.15 & $1.05-1.26$ & 0.004 & 1.10 & $1.001-1.21$ & 0.048 \\
\hline \multicolumn{7}{|l|}{ Hubei Province } \\
\hline No & 1 & & & 1 & & \\
\hline Yes & 1.58 & $1.34-1.87$ & $<0.001$ & 1.64 & $1.39-1.93$ & $<0.001$ \\
\hline \multicolumn{7}{|l|}{ Grade } \\
\hline Junior grade one & 1 & & & 1 & & \\
\hline Junior grade two & 1.14 & $0.94-1.39$ & 0.19 & 1.22 & $0.99-1.50$ & 0.06 \\
\hline Junior grade three & 1.40 & $1.11-1.75$ & 0.04 & 1.32 & $1.04-1.67$ & 0.02 \\
\hline Senior grade one & 1.88 & $1.56-2.29$ & $<0.001$ & 1.57 & $1.28-1.92$ & $<0.001$ \\
\hline Senior grade two & 2.42 & $1.97-2.97$ & $<0.001$ & 2.06 & $1.66-2.54$ & $<0.001$ \\
\hline Senior grade three & 3.25 & $2.54-4.15$ & $<0.001$ & 3.05 & $2.37-3.91$ & $<0.001$ \\
\hline \multicolumn{7}{|l|}{ Awareness of COVID-19 } \\
\hline COVID-19 Knowledge & 0.92 & $0.90-0.95$ & $<0.001$ & 0.97 & $0.94-0.99$ & 0.006 \\
\hline Prevention and control measures & 0.91 & $0.88-0.93$ & $<0.001$ & 0.93 & $0.91-0.96$ & $<0.001$ \\
\hline Projections of COVID-19 trend & 0.87 & $0.85-0.88$ & $<0.001$ & 0.83 & $0.81-0.85$ & $<0.001$ \\
\hline
\end{tabular}

symptoms $\left(\mathrm{OR}_{\mathrm{DE}}=1.58,95 \%\right.$ CI 1.34-1.87; $\mathrm{OR}_{\mathrm{AN}}=1.64$, 95\% CI 1.39-1.93). In terms of grades, senior high school was a risk factor for depressive and anxiety symptoms; the higher the grade, the greater the risk of depressive and anxiety symptoms. However, for junior high school, we only found junior grade three to be a risk factor for depressive and anxiety symptoms $\left(\mathrm{OR}_{\mathrm{DE}}=1.40,95 \% \mathrm{CI} 1.11-1.75\right.$; $\left.\mathrm{OR}_{\mathrm{AN}}=1.32,95 \% \mathrm{CI} 1.04-1.67\right)$. We also found that awareness of COVID-19 (COVID-19 knowledge, prevention and control measures, and projections of COVID-19 trend) were protective factors against depressive and anxiety symptoms.

\section{Discussion}

In this large-scale, cross-sectional epidemiological study, the prevalence of depressive and anxiety symptoms in middle and high school students of China was $43.7 \%$ and $37.4 \%$, respectively. In addition, the prevalence of comorbid depressive and anxiety symptoms among the students was $31.3 \%$. The prevalence of depressive symptoms was higher than the figures found in Sweden (8.8\%) and Japan (14.9\%) in the absence of epidemics [43]. In China, adolescents had a higher incidence of depressive symptoms during COVID-19 than adults [27]. The prevalence of depressive symptoms is significantly influenced by sociocultural and economic contexts [44, 45]; therefore, it needs to be assessed in different countries and regions. According to a pre-COVID-19 meta-analysis, the general prevalence of depressive symptoms among Chinese children and adolescents was $15.4 \%$ [46]. The reported prevalence of anxiety disorder varied widely in previous studies. The lowest rate reported was 2.6\% in American 11-year-olds [47], and the highest was $41.2 \%$ in Japanese 7-9-year-olds [48]. One study found that the prevalence of anxiety disorders among Chinese children and adolescents was $6.06 \%$ [49]. Studies have shown that the incidence of anxiety symptoms among Chinese high school students ranges from 13.7 to $24.5 \%$ [50, 51]. Our current results were similar to those of the public perception of anxiety at the peak phase during H1N1 [52]. Clearly, the prevalence of depressive and anxiety symptoms in adolescents was higher than in the general population in China in the early and peak periods of COVID-19. Thus, although the infection rate of COVID-19 in China is leveling off [53] (the infection rate of COVID-19 was $11.4 \times 10^{-4}$ in Hubei province and $0.03 \times 10^{-4}-0.2 \times 10^{-4}$ in other provinces [54]) during our survey, the rate of depressive and anxiety symptoms among adolescents was still high. This is a warning that we should not ignore the psychological health problems of young people just because the epidemic has eased. In the follow-up work, we should also pay attention to the changes of depressive and anxiety symptoms in these children.

Both genetic factors and external environmental factors (stressful life events in particular) are considered to be involved in the onset of depression [22-24]. In the face of stressful events, everyone will develop anxiety and depressive symptoms. As a sensitive group, adolescents are particularly worthy of attention.

In pace with the wide spread of COVID-19 outside China, our findings provide important guidance for the development of psychological support strategies in China and other affected areas. At present, the epidemic has been well 
controlled in China, but it is still spreading outside China [2]. Thus, health care systems and the public must be well prepared for medical treatment and psychological issues [55]. Our findings have clinical and policy implications. First, health authorities need to identify high-risk groups according to social population information to carry out early psychological intervention. Our socio-demographic data show that female students have suffered from greater psychological impact, as well as higher levels of stress, anxiety, and depressive symptoms, during the COVID-19 outbreak. This finding is consistent with previous epidemiological studies that found that women were at a higher risk of depression [56]. A similar study among students found that female students were more likely to be anxious [57]. Furthermore, we found that the proportion of anxiety and depressive symptoms among students living in rural areas is significantly higher than that in urban areas, which is closely related to their poor economic situation. This is also consistent with previous studies, with some studies finding that the rate of emotional disorder is nearly twice as high among the poor as among the wealthy [44, 58]. Additionally, senior grade three students had higher levels of anxiety and depression than senior grade one students and the highest rate among all the students. As senior grade three students face the most important test of their lives (the college entrance examination), the COVID-19 outbreak disrupts their normal pace of learning, leading to increased pressure; it can be inferred that the academic pressure causes more pressure on students $[59,60]$. Junior three students facing high school entrance examinations have the same problem. In China, students in junior three must have good grades to get into a good high school, they also had more anxiety and depressive symptoms.

Moreover, our findings suggest that the level of knowledge and the prevention and control measures for COVID19 may have protective psychological effects in the early stages of the epidemic. It can be seen that strengthening the publicity of COVID-19 knowledge and precautionary measures adopted to prevent the spread of COVID-19 can reduce the anxiety and depression levels of the public. This is consistent with previous studies finding that wearing a mask and practicing hand hygiene reduces the level of anxiety and depression during the epidemic [27]. However, press/ media coverage can also adversely affect anxiety and depressive symptoms, false information and false reports about COVID-19 can aggravate anxiety and depressive symptoms in the general public [61]. The latest and most accurate information, such as the number of people who have recovered, and the progress of medicines and vaccines, can reduce anxiety levels [27]. Therefore, the government and health authorities should provide accurate information on the epidemic situation, refute rumors in time, and reduce the impact of rumors on the public emotional state. Strengthening prevention and control measures can not only block the spread of disease but also provide a sense of security, thus bringing potential psychological benefits. Therefore, governments and health authorities should ensure that infrastructure is in place to produce and provide adequate quantities of masks, hand sanitizer, and other personal hygiene products during the COVID-19 epidemic. Positive and optimistic attitude towards the development of COVID-19 epidemic was also a protective factor against depressive and anxiety symptoms. The epidemiology of infection rates and deaths likely affects depressive and anxiety symptoms. During the H1N1 pandemic, public anxiety was at its worst at the height of the epidemic, and has declined as the epidemic has eased $[25,26]$.

Due to the outbreak of COVID-19, major cities in China have shut down schools at all levels indefinitely. Although education authorities have developed online portals and web-based applications to provide lectures or other teaching activities, the uncertainty and potential negative effects on academic development will have adverse effects on students' psychological health. Besides, students are also required to report daily health conditions, limit their travel, thus entailing that they are isolated at home, which can lead to anxiety and depression. Because students are currently taking online classes at home, and are receptive to smartphone apps [62], health authorities can consider providing online or smartphone-based psychological interventions. Online platforms can also provide online psychological support for students who stay at home most of the time during the epidemic and can reduce the risk of virus transmission due to face-toface contact. In addition, when conducting online teaching, teachers should also pay attention to the assessment of students' anxiety and depressive symptoms, communicating with their parents in a timely manner so as to implement effective intervention.

This study has two limitations. One possible bias could have led to underestimating the prevalence of anxiety and depression. This sample was a non-probability sample, which is a sample of voluntary participants. For some areas with a severe epidemic situation, anxiety and depression rates may be higher. However, due to the influence of anxiety and depression, students may not be willing to participate in the questionnaire survey [63], and there may be a certain deviation in the response population. Furthermore, due to the online questionnaire being a self-report evaluation, the indicated levels of anxiety and depression may not always be consistent with the evaluation of mental health professionals.

In conclusion, our results show there is a high prevalence of psychological health problems among adolescents, which is negatively associated with the level of knowledge about and the prevention and control measures for COVID-19. These findings suggest that the government needs pay more attention to psychological health among adolescents while combating COVID-19. Fortunately, the Chinese government 
has provided psychological health services through various channels, including hotlines, online consultation, and outpatient consultation [28], but more attention should be paid to depression and anxiety, especially among adolescents.

Acknowledgements The authors would like to thank Jia-Ling Xue and Juan Liang for all their hard work and significant contributions to the study. We also thank Accdon (www.letpub.com) for English language editing.

Author contributions Each author have made substantial contributions to the conception and design of the work; or the acquisition, analysis, or interpretation of data; or revised it to have approved the submitted version. All authors have agreed to be personally accountable for the author's own contributions and to ensure that questions related to the accuracy or integrity of any part of the work are appropriately investigated, resolved, and the resolution documented in the literature.

Funding This work was supported by Capital Foundation of Medicine Research and Development (2018-3-2132); the Special Foundation of Beijing Municipal Science \& Technology Commission (Z171100001017001).

Data availability The data that support the findings of this study are available from the corresponding author upon reasonable request.

\section{Compliance with ethical standards}

Conflict of interest The authors declare that they have no competing interests.

Ethics approval and consent to participate Ethics Committee of Beijing HuiLongGuan Hospital approved the study (2020-07).

\section{References}

1. Organization WH (2020) WHO Director-General's statement on IHR Emergency Committee on Novel Coronavirus (2019-nCoV). https://www.hoint/dg/speeches/detail/who-director-general-s-state ment-on-ihr-emergency-committee-on-novel-coronavirus-(2019ncov). Accessed 30 Mar 2020

2. Organization WH (2020) Coronavirus disease 2019 (COVID-19) Situation Report - 62 https://www.hoint/docs/default-source/ coronaviruse/situation-reports/20200322-sitrep-62-covid-19pdf ?sfvrsn=f7764c46_2. Accessed 30 Mar 2020

3. China NHCotPsRo (2020) Latest Situation Report of Coronavirus disease 2019 (COVID-19) https://www.nhcgoven/yjb/s7860 /202003/fbd8871d80574991a4913cd180f83402shtml. Accessed 30 Mar 2020

4. Bao Y, Sun Y, Meng S, Shi J, Lu L (2020) 2019-nCoV epidemic: address mental health care to empower society. Lancet 395(10224):e37-e38. https://doi.org/10.1016/S0140 $-6736(20) 30309-3$

5. Kang L, Li Y, Hu S, Chen M, Yang C, Yang BX, Wang Y, Hu J, Lai J, Ma X, Chen J, Guan L, Wang G, Ma H, Liu Z (2020) The mental health of medical workers in Wuhan, China dealing with the 2019 novel coronavirus. Lancet Psychiatry 7(3):e14. https:// doi.org/10.1016/s2215-0366(20)30047-x

6. Membride $\mathrm{H}$ (2016) Mental health: early intervention and prevention in children and young people. Br J Nurs 25(10):552-554. https://doi.org/10.12968/bjon.2016.25.10.552 (556-557)
7. Organization WH (2012) Adolescent mental health-Mapping actions of nongovernmental organizations and other international development organizations. https://www.hoint/mental_health/ publications/adolescent_mental_health/en/. Accessed 30 Mar 2020

8. Organization WH (2019) Adolescent mental health. https://www. whoint/news-room/fact-sheets/detail/adolescent-mental-health. Accessed 30 Mar 2020

9. Kieling C, Baker-Henningham H, Belfer M, Conti G, Ertem I, Omigbodun O, Rohde LA, Srinath S, Ulkuer N, Rahman A (2011) Child and adolescent mental health worldwide: evidence for action. Lancet 378(9801):1515-1525. https://doi.org/10.1016/ s0140-6736(11)60827-1

10. Kessler RC, Angermeyer M, Anthony JC, Demyttenaere K, Gasquet I, Gluzman S, Gureje O, Haro JM, Kawakami N, Karam A, Levinson D, Medina Mora ME, Oakley Browne MA, Posada-Villa J, Stein DJ, Adley Tsang CH, Aguilar-Gaxiola S, Alonso J, Lee S, Heeringa S, Pennell BE, Berglund P, Gruber MJ, Petukhova M, Chatterji S, Ustün TB (2007) Lifetime prevalence and ageof-onset distributions of mental disorders in the World Health Organization's World Mental Health Survey Initiative. World Psychiatry 6(3):168-176

11. Liu X, Sun Z, Neiderhiser JM, Uchiyama M, Okawa M, Rogan W (2001) Behavioral and emotional problems in Chinese adolescents: parent and teacher reports. J Am Acad Child Adolesc Psychiatry 40(7):828-836. https://doi.org/10.1097/00004583-20010 $7000-00018$

12. Liu HZJ (2004) Norm of symptom checklist (Scl-90) in chinese middle school students. Chin J Epidemiol 18(2):88-90 (In Chinese)

13. Tang GZ, Guo LT, Huang XZ (2005) An epidemiological study on mental problems in adolescents in Chengdu, China. Zhonghua Liu Xing Bing Xue Za Zhi 26(11):878-881 (In Chinese)

14. Zhang Y, Wang SQ (2007) Epidemiological survey on psychobehavior problems of children aged 4-16. Matern Child Health Care China 22(13):1829-1830 (In Chinese)

15. Wang JN, Liu L, Wang L (2014) Prevalence and associated factors of emotional and behavioural problems in Chinese school adolescents: a cross-sectional survey. Child Care Health Dev 40(3):319-326. https://doi.org/10.1111/cch.12101

16. Zhang SP (2006) Mental health. In: China Children Center, Children's survival and development in China: Data and analysis. China Women Publishing House. pp 154-157 (In Chinese)

17. Cui Y, Li F, Leckman JF, Guo L, Ke X, Liu J, Zheng Y, Li Y (2020) The prevalence of behavioral and emotional problems among Chinese school children and adolescents aged 6-16: a national survey. Eur Child Adolesc Psychiatry. https://doi. org/10.1007/s00787-020-01507-6

18. Health DO (2015) Future in mind: promoting, protecting and improving our children and young people's mental health and wellbeing.

19. Membride HMJ, Atkinson J (2015) The challenge of meeting children's mental health needs. Br J Sch Nurs 10(1):19-25. https:// doi.org/10.12968/bjsn.2015.10.1.19

20. Glowinski AL, D’Amelio G (2016) Depression is a deadly growing threat to our youth: time to rally. Pediatrics. https://doi. org/10.1542/peds.2016-2869

21. Mojtabai R, Olfson M, Han B (2016) National trends in the prevalence and treatment of depression in adolescents and young adults. Pediatrics. https://doi.org/10.1542/peds.2016-1878

22. Kendler KS, Karkowski LM, Prescott CA (1999) Causal relationship between stressful life events and the onset of major depression. Am J Psychiatry 156(6):837-841. https://doi.org/10.1176/ ajp.156.6.837

23. Uchida S, Hara K, Kobayashi A, Otsuki K, Yamagata H, Hobara T, Suzuki T, Miyata N, Watanabe Y (2011) Epigenetic status of 
Gdnf in the ventral striatum determines susceptibility and adaptation to daily stressful events. Neuron 69(2):359-372. https://doi. org/10.1016/j.neuron.2010.12.023

24. Yang L, Zhao Y, Wang Y, Liu L, Zhang X, Li B, Cui R (2015) The effects of psychological stress on depression. Curr Neuropharmacol 13(4):494-504. https://doi.org/10.2174/1570159x1304150 831150507

25. Liao Q, Cowling BJ, Lam WW, Ng DM, Fielding R (2014) Anxiety, worry and cognitive risk estimate in relation to protective behaviors during the 2009 influenza A/H1N1 pandemic in Hong Kong: ten cross-sectional surveys. BMC Infect Dis 14:169. https ://doi.org/10.1186/1471-2334-14-169

26. Van Bortel T, Basnayake A, Wurie F, Jambai M, Koroma AS, Muana AT, Hann K, Eaton J, Martin S, Nellums LB (2016) Psychosocial effects of an Ebola outbreak at individual, community and international levels. Bull World Health Organ 94(3):210-214. https://doi.org/10.2471/blt.15.158543

27. Wang C, Pan R, Wan X, Tan Y, Xu L, Ho CS, Ho RC (2020) Immediate Psychological Responses and Associated Factors during the Initial Stage of the 2019 Coronavirus Disease (COVID-19) Epidemic among the General Population in China. Int J Environ Res Public Health. https://doi.org/10.3390/ijerph17051729

28. China NHCotPsRo (2020) Guideline for psychological crisis intervention during 2019-nCoV. https://www.goven/xinwen/202001/27/content 5472433htm. Accessed 30 Mar 2020

29. Shultz JM, Baingana F, Neria Y (2015) The 2014 Ebola outbreak and mental health: current status and recommended response. JAMA 313(6):567-568. https://doi.org/10.1001/jama.2014.17934

30. Spitzer RL, Kroenke K, Williams JB (1999) Validation and utility of a self-report version of PRIME-MD: the PHQ primary care study. Primary care evaluation of mental disorders. Patient health questionnaire. JAMA 282(18):1737-1744. https://doi. org/10.1001/jama.282.18.1737

31. Kroenke K, Spitzer RL, Williams JB (2001) The PHQ-9: validity of a brief depression severity measure. J Gen Intern Med 16(9):606-613. https://doi.org/10.1046/j.1525-1497.2001.01600 9606.x

32. Wittkampf KA, Naeije L, Schene AH, Huyser J, van Weert HC (2007) Diagnostic accuracy of the mood module of the Patient Health Questionnaire: a systematic review. Gen Hosp Psychiatry 29(5):388-395. https://doi.org/10.1016/j.genhosppsy ch.2007.06.004

33. Levis B, Benedetti A, Thombs BD (2019) Accuracy of Patient Health Questionnaire-9 (PHQ-9) for screening to detect major depression: individual participant data meta-analysis. BMJ 365:11476. https://doi.org/10.1136/bmj.11476

34. Wang W, Bian Q, Zhao Y, Li X, Wang W, Du J, Zhang G, Zhou Q, Zhao M (2014) Reliability and validity of the Chinese version of the Patient Health Questionnaire (PHQ-9) in the general population. Gen Hosp Psychiatry 36(5):539-544. https://doi. org/10.1016/j.genhosppsych.2014.05.021

35. Zhang YL, Liang W, Chen ZM, Zhang HM, Zhang JH, Weng XQ, Yang SC, Zhang L, Shen LJ, Zhang YL (2013) Validity and reliability of Patient Health Questionnaire-9 and Patient Health Questionnaire-2 to screen for depression among college students in China. Asia Pac Psychiatry 5(4):268-275. https://doi.org/10.1111/ appy. 12103

36. Alharbi R, Alsuhaibani K, Almarshad A, Alyahya A (2019) Depression and anxiety among high school student at Qassim Region. J Family Med Prim Care 8(2):504-510. https://doi. org/10.4103/jfmpc.jfmpc_383_18

37. Liu Yang ZW, Cai J (2017) Relation of anxiety and depression to lifestyle in junior high school students. Chin Ment Health J 31(3):235-240 (In Chinese)

38. Spitzer RL, Kroenke K, Williams JB, Löwe B (2006) A brief measure for assessing generalized anxiety disorder: the GAD-7.
Arch Intern Med 166(10):1092-1097. https://doi.org/10.1001/ archinte.166.10.1092

39. Xu WF, Peng Y, Chen BQ, Peng ZY, Zhao JL, Yu GL (2018) Assessment of anxiety and depression by self-rating scales of GAD-7 and PHQ-9 in cardiovascular outpatients. World Latest Med Inf 18(16):12-14 (In Chinese)

40. He XYLC, Qian J et al (2010) Reliability and validity of a generalized anxiety scale in general hospital outpatients. Shanghai Arch Psychiatry 22(4):200-203 (In Chinese)

41. Wang Y, Chen R, Zhang L (2018) Evaluation of the reliability and validity of the generalized anxiety disorder 7-item scale among inpatients in general hospital. J Clin Psychiatry 28(3):168-171 (In Chinese)

42. Tiirikainen K, Haravuori H, Ranta K, Kaltiala-Heino R, Marttunen M (2019) Psychometric properties of the 7-item Generalized Anxiety Disorder Scale (GAD-7) in a large representative sample of Finnish adolescents. Psychiatry Res 272:30-35. https ://doi.org/10.1016/j.psychres.2018.12.004

43. Rao WW, Xu DD, Cao XL, Wen SY, Che WI, Ng CH, Ungvari GS, He F, Xiang YT (2019) Prevalence of depressive symptoms in children and adolescents in China: a meta-analysis of observational studies. Psychiatry Res 272:790-796. https://doi. org/10.1016/j.psychres.2018.12.133

44. Kleinman A (2004) Culture and depression. N Engl J Med 351(10):951-953. https://doi.org/10.1056/NEJMp048078

45. Compton WM, Conway KP, Stinson FS, Grant BF (2006) Changes in the prevalence of major depression and comorbid substance use disorders in the United States between 1991-1992 and 2001-2002. Am J Psychiatry 163(12):2141-2147. https:// doi.org/10.1176/ajp.2006.163.12.2141

46. Li JL, Chen X, Zhao CH, Xu Y (2016) Prevalence of depression in Chinese children and adolescents: a Meta-analysis. Chin J Child Health Care 24(3):295-298 (In Chinese)

47. Costello EJ, Mustillo S, Erkanli A, Keeler G, Angold A (2003) Prevalence and development of psychiatric disorders in childhood and adolescence. Arch Gen Psychiatry 60(8):837-844. https://doi.org/10.1001/archpsyc.60.8.837

48. Sugawara M, Mukai T, Kitamura T, Toda MA, Shima S, Tomoda A, Koizumi T, Watanabe K, Ando A (1999) Psychiatric disorders among Japanese children. J Am Acad Child Adolesc Psychiatry 38(4):444-452. https://doi.org/10.1097/00004583199904000-00018

49. Xiaoli Y, Chao J, Wen P, Wenming X, Fang L, Ning L, Huijuan M, Jun N, Ming L, Xiaoxia A, Chuanyou Y, Zenguo F, Lili L, Lianzheng Y, Lijuan T, Guowei P (2014) Prevalence of psychiatric disorders among children and adolescents in northeast China. PLoS ONE 9(10):e111223. https://doi.org/10.1371/journ al.pone. 0111223

50. Hu M, Zheng L, Xia Q, Deng YX et al (2007) An investigation into the prevalence and related factors of anxiety in middle school students of Hunan Province. Chin J Clin Psychol 15(6):592-594 (In Chinese)

51. Wan PF, Sun YJ, Jin Y (2005) Characteristics of anxiety and the related risk factors among adolescent students in Dalian City. Chin J Behav Med Sci 14(5):36-438 (In Chinese)

52. Bults M, Beaujean DJ, Richardus JH, Voeten HA (2015) Perceptions and behavioral responses of the general public during the 2009 influenza A (H1N1) pandemic: a systematic review. Disaster Med Public Health Prep 9(2):207-219. https://doi. org/10.1017/dmp. 2014.160

53. Center. JHUaMCR (2020) https://www.coronavirusjhuedu/ maphtml. Accessed 5 Apr 2020

54. Dingxiangyuan (2020) COVID-19 Pandemic Real-time Report. https://ncov.dxy.cn/ncovh5/view/pneumonia?from=dxy\&sourc $\mathrm{e}=\&$ link$=\&$ share. Accessed 5 Apr 2020 
55. Patel A (2020) Jernigan DB (2020) Initial public health response and interim clinical guidance for the 2019 novel coronavirus outbreak-United States, December 31, 2019-February 4. MMWR Morb Mortal Wkly Rep 69(5):140-146. https://doi.org/10.15585 /mmwr.mm6905e1

56. Lim GY, Tam WW, Lu Y, Ho CS, Zhang MW, Ho RC (2018) Prevalence of depression in the community from 30 countries between 1994 and 2014. Sci Rep 8(1):2861. https://doi.org/10.1038/s4159 8-018-21243-x

57. Putwain DW (2007) Test anxiety in UK schoolchildren: prevalence and demographic patterns. Br J Educ Psychol 77(Pt 3):579_ 593. https://doi.org/10.1348/000709906x161704

58. Slobodskaya HR, Semenova NB (2016) Child and adolescent mental health problems in Tyva Republic, Russia, as possible risk factors for a high suicide rate. Eur Child Adolesc Psychiatry 25(4):361-371. https://doi.org/10.1007/s00787-015-0743-Z

59. Yuan F, Li ZS, Yang YL, Mou Y (2018) Prevalence of anxiety tested with Test Anxiety Scale( TAS) in senior three students: a meta-analysis. Chin J Sch Health 39(9):1324-1328 (In Chinese)
60. Zhang YJ, Yang F, Liu SF et al (2005) Mental health states of senior high school students before the college entrance examination. Chin J Clin Rehabili 9(4):92-93 (In Chinese)

61. Xinhua (2020) Bat soup, biolab, crazy numbers...Misinformation "infodemic" on novel coronavirus exposed. https://www.xinhu anetcom/english/2020-02/04/c_138755586htm Accessed 5 Apr 2020

62. Do TTT, Le MD, Van Nguyen T, Tran BX, Le HT, Nguyen HD, Nguyen LH, Nguyen CT, Tran TD, Latkin CA, Ho RCM, Zhang MWB (2018) Receptiveness and preferences of health-related smartphone applications among Vietnamese youth and young adults. BMC Public Health 18(1):764. https://doi.org/10.1186/ s12889-018-5641-0

63. Allgulander C (1989) Psychoactive drug use in a general population sample, Sweden: correlates with perceived health, psychiatric diagnoses, and mortality in an automated record-linkage study. Am J Public Health 79(8):1006-1010. https://doi.org/10.2105/ ajph.79.8.1006 